\title{
O Ato de Avaliar na Educação Infantil: Divergências Conceituais Entre as Avaliações Classificatória e Diagnóstica
}

\section{The Evaluation Act at Childhood Education: Conceptual Divergences between Classificatory and Diagnostic Evaluations}

\author{
Gisele Reinaldo da Silva*a; Paula Cristina Teixeira Freire ${ }^{\mathrm{b}}$ \\ ${ }^{a}$ Universidade Federal do Rio de Janeiro, Programa de Pós-Graduação Stricto Sensu em Letras. RJ, Brasil. \\ ${ }^{\mathrm{b}}$ Centro Universitário Carioca. RJ, Brasil. \\ *E-mail: giselere@gmail.com
}

\begin{abstract}
Resumo
Este artigo tem como proposta comparar as avaliações Classificatória e Diagnóstica no que se refere à adequabilidade de sua aplicação no âmbito da educação infantil. Objetiva-se, neste estudo, compreender como a avaliação Diagnóstica contribui na construção da aprendizagem da criança, ao analisar seus estágios de aquisição de conhecimentos de maneira significativa, à medida que identifica potencialidades e dificuldades do educando antes e durante cada fase de ensino. Em contrapartida, defende-se, neste estudo, a inadequabilidade da adoção da avaliação Classificatória na educação infantil, em sua proposta de classificar indivíduos conforme critérios padronizados e previamente estabelecidos, gerando hierarquização entre os educandos, avaliados de maneira pontual e quantitativa, através de graus e notas. Promove-se, assim, uma revisão bibliográfica qualitativa acerca de concepções teórico-críticas comparativas entre as distintas formas de avaliar, a partir da qual se conclui que o ato de avaliar não é um ato neutro que se encerra na confirmação, mas, sim, um ato construtivo, amoroso, inclusivo e dialógico, distintos dos exames classificatórios, que são excludentes. Desta forma, esta pesquisa destaca-se por contribuir para o desenvolvimento da criança como ser social, através do fomento de suas habilidades afetiva, emocional e cognitiva, propiciado pela interação e aprendizagem com o meio em que vive.
\end{abstract}

Palavras-chave: Formas de Avaliação. Primeira Infância. Avaliação Somativa. Avaliação Analítica.

\begin{abstract}
This article aims to compare Classificatory and Diagnostic evaluation concerning the applicability in the environment of early childhood education. It seeks to understand how the Diagnostic evaluation contributes to the child learning process, by analyzing the stages of knowledge acquisition in a significant way, as it identifies learners' potentialities and difficulties before and during each educational phase. In contrast, this study defends the inadequacy of adopting the Classificatory evaluation at early childhood education, in its proposal of classifying individuals according to standardized and previously established criteria, creating a hierarchy among students, assessed in a punctual and quantitative way, through grades. Thus, a qualitative bibliographic review about comparative theoretical-critical conceptions between the different ways of evaluating is promoted, from which we conclude that the act of evaluating is not a neutral act that ends in the confirmation, but a constructive, loving, inclusive and dialogical act, discrete from the classificatory examination that is exclusionary. Thus, this research stands out for contributing to child development as a social being, through encouraging their affective, emotional and cognitive skills, promoted by the interaction and learning in the environment they live.
\end{abstract}

Keywords: Assessment Methods. Early Childhood. Somative Evaluation. Analytic Evaluation.

\section{Introdução}

Este artigo aborda as divergências conceituais entre as Avaliações Classificatória e Diagnóstica, no ato de avaliar em âmbito da educação infantil, ressaltando como a maneira de avaliar neste segmento constituinte de um pilar na formação humana pode inibir ou potencializar as habilidades do educando, a depender das práticas pedagógicas adotadas.

É sabido que existem diferentes formas de avaliar e uma delas é o modelo da Avaliação Classificatória, que analisa os resultados baseando-se em um processo quantitativo, o qual, conforme a premissa deste estudo, nem sempre aponta onde estão as verdadeiras falhas que culminam nos resultados do fracasso escolar. Entretanto, pautando-nos, sobretudo, nas perspectivas teórico-críticas de Luckesi (2000, 2011); Hoffmann (1996, 2010); Kramer (1982, 1989); Freire (1994), Lacerda e Souza (2013); Cesar e Souza (2016); Schlindwein e
Dias (2018), compreendemos que, na Avaliação Diagnóstica, priorizam-se os processos de ensino e aprendizagem, não se embasando em notas hierarquizantes entre os educandos, mas, sim, em uma busca por identificar seus estágios de aprendizagem, a fim de aprimorar os processos educativos.

Nesse sentido, esta pesquisa parte do pressuposto de ser a Avaliação Diagnóstica a maneira mais adequada do ato de avaliar na educação infantil e, a partir desta premissa, dedica-se à revisão de literatura pareando comparativa e qualitativamente concepções teórico-críticas de autores especialistas em avaliação na educação, a fim de verificar a adequabilidade destas práticas avaliativas - Classificatória e Diagnóstica - no contexto da educação infantil. 


\section{Desenvolvimento}

\subsection{Metodologia}

Para esta pesquisa, houve a consulta e análise de documentos oficiais de educação do Brasil, tais como a Lei n. 9394 (BRASIL, 1996), a Política Nacional de Educação Infantil: pelos direitos das crianças de zero a seis anos à educação (BRASIL, 2006) e o Referencial Curricular Nacional para a Educação Infantil (BRASIL, 1998) no tocante às diretrizes relacionadas à avaliação. Além destes, baseamonos nas concepções teórico-críticas de autores especialistas na área de avaliação, tais como Hoffmann $(1996,2010)$, Luckesi (2000, 2011), Kramer (1982, 1989) e Freire (1994). Buscamos, ainda, a seleção de artigos científicos contemporâneos sobre avaliação, publicados nos últimos 5 (cinco) anos, a partir das seguintes palavras-chave: a) Avaliação infantil, b) Construção do desenvolvimento infantil e c) Educação infantil. Para tanto, utilizamos a plataforma SciElo como base de busca e a seleção dos textos - Lacerda e Souza (2013); Cesar e Souza (2016); Schlindwein e Dias (2018) - deu-se com base na pertinência das ideias em relação ao propósito desta pesquisa.

\subsection{O Ato de Avaliar na Educação Infantil}

Conforme Luckesi (2000), a avaliação é um recurso pedagógico útil e necessário para amparar os educadores e os educandos em sua construção do conhecimento. A avaliação não pode e não deve continuar sendo uma ameaça à prática educativa, visto que necessita ser amorosa, inclusiva, dinâmica e construtiva; distinta dos exames que, na visão do autor, são excludentes e classificatórios.

Avaliar o educando implica acolhê-lo no seu modo de ser, para, a partir de então, se decidir o caminho de ensino a se percorrer, em seus ajustes e adequabilidades. Não é possível avaliar o estudante caso este seja julgado, ou mesmo, rechaçado previamente. Luckesi (2000) defende que a disposição de acolher não é inata ao ser humano, mas construída intencionalmente, e precisamos estar atentos ao modo como observamos as informações expostas pelos alunos, em sua expressão oral e escrita, em consonância à conduta comportamental adotada. Desta maneira, a avaliação só nos garantirá condições de obtermos uma melhor qualidade de coleta de informação, se estivermos dispostos a acolher o sujeito, para a partir daí construirmos o conhecimento.

Luckesi (2000) aponta dois métodos correlacionados: o diagnóstico e a tomada de decisão, não sendo possível uma decisão sem um diagnóstico e um diagnóstico sem uma decisão. O processo de diagnosticar é o que constitui uma constatação de qualificação do objeto da avaliação, tendo como base suas propriedades específicas. O autor defende, assim, que o ato de avaliar não é um ato neutro que se encerra na confirmação, mas constitui um ato dialógico e afetivo que se aplica na decisão do que fazer. Sem esse ato, a ação de avaliar não se concluiria.

Condizente com Luckesi (2000), Martins Filho e Castro
(2018) defendem que o objetivo principal da avaliação não é o seu resultado final, mas, sim, o processo pedagógico experimentado pelas crianças, em constantes trocas simbólicas com os profissionais que a auxiliam em sua construção do conhecimento, bem como com a família e sociedade às quais estão interligadas.

Avaliar inicia-se no ato de diagnosticar para depois seguir para a coleta de dados relevantes, que caracterizem o estado da aprendizagem do educando. Luckesi (2000) explica a necessidade de se considerar para a avaliação: a) dados relevantes; b) instrumentos; c) utilização dos instrumentos. Enfatiza que os dados coletados são essenciais para o plano de ensino e devem ser produzidos de forma coerente e satisfatória, tanto do ponto de vista científico como políticopedagógico, visto que é a teoria pedagógica que dá o norte à prática educativa.

Marins Filho e Castro (2018) complementam essa prerrogativa ao definirem que avaliar é estar vinculado aos seguintes processos educativos: planejar, observar, registar e documentar. A defesa dos autores é de que este método propicia uma avaliação voltada ao próprio percurso do conhecimento obtido pelos educandos.

Assim, a prática faz a mediação entre a teoria pedagógica e a vivência em sala de aula. Todavia, os instrumentos de avaliação da aprendizagem não podem ser quaisquer instrumentos, mas o adequado para a coleta de dados: a) ao tipo de conduta e de habilidades que estão pretendendo avaliar; b) aos conteúdos planejados, realizados no processo de ensino; c) na linguagem, na clareza e na comunicação.

Luckesi (2000) declara que para suceder a avaliação da aprendizagem, o professor necessita simplificar o acolhimento das informações expostas pelos alunos e abrir espaço para o diálogo. Desta forma, o professor inicia seu método pedagógico, levando em consideração a constituição integral do aluno, atingindo assim, o ponto básico para prosseguir nas atividades e na avaliação em qualquer prática educativa.

Na visão de Luckesi (2000), em relação aos educandos, o acolhimento tem como significado estar aberto para recebêlos, compreendê-los e dialogar com eles, para, enfim, ajudálos, e somente depois, verificar suas habilidades.

Diante do exposto, Luckesi (2011 apresenta dois momentos do processo avaliativo: o primeiro pontua o ponto de vista psicológico do educando, sendo relevante estar ciente e valorizar o seu esforço em dar conta dos conteúdos indicados para o estudo. O segundo momento é a observação do ponto de vista técnico e científico da prática da avaliação. Se pretendemos saber se o aluno aprendeu o que efetivamente ensinamos, devemos construir um instrumento que cubra todos os conteúdos essenciais que o estudante efetivamente necessita compreender para o seu desenvolvimento escolar.

Sendo assim, Luckesi (2011) renova o entendimento sobre o modo de agir dos professores, os quais, em primeiro lugar, devem ter clareza do que se deseja com o projeto proposto 
que orienta as condutas educativas; e, em segundo, investir para que o resultado seja obtido conforme o planejado, não existindo resultados bem-sucedidos sem investimentos adequados e persistentes. E, por último, usar a avaliação como recurso diagnóstico, para a obtenção do melhor resultado.

A proposição de Luckesi (2011), referente ao instrumento de coleta de dados para a avaliação do desempenho, é que deve respeitar o esforço do aluno no estudar e no aprender, sem enganá-lo. Para isso, deverá ser constituído de forma: 1- metodológica, cientificamente adequada e planejada; 2- a partir da aplicação de questões precisas sem indução ao erro; 3- cada questão deve conter um único conteúdo; 4- questões devem ser adotadas com apresentação de linguagem clara; 5- questões dúbias e confusas deverão ser suprimidas de todo e qualquer instrumento. A partir destas reflexões, essas mudanças de conduta nas práticas educativas e avaliativas são essenciais para a clara e crítica consciência na tomada de decisão, buscando aprimorar a busca da democratização do saber.

Luckesi (2011) esclarece que a criança necessita tomar posse desse determinado conteúdo como seu, constituinte do recurso da democratização do saber necessário a todos. Porém, a aprendizagem significativa deve ir além do estritamente necessário e ingressar no reino do criativo: manifesta-se plena no âmbito da criação ou recriação do conhecimento, das habilidades, das performances, da investigação científica, das soluções tecnológicas novas. Deve-se ser ensinado e treinado em nossos estudantes não só o esperado deles nas ocasiões de aplicação de instrumentos para a coleta de dados sobre o desempenho, mas arriscar ir além do que já se aprendeu, e para isso, importa investir na exercitação da prática.

Martins Filho e Castro (2018) criticam o entendimento da avaliação como um método de mensuração do saber, um controle social, no sentido de classificar, hierarquizar, homogeneizar e normalizar os estudantes, tendo como base sempre os mesmos objetivos de controle e parâmetro.

Com isso, Martins Filho e Castro (2018) ratificam a perspectiva de Luckesi (2000), que defende o seguinte: o instrumento de coleta de dados para a avaliação da aprendizagem que parece ser somente para desvendar a aquisição de conhecimento pontual da criança em relação aos conteúdos ensinados, comumente, poderá ser classificado como avaliação que serve para detectar o desenvolvimento restritivo, diferente do domínio, que é o necessário para todos. Colocado em análise, este método avaliativo não pode nem mesmo ser classificado na categoria do desenvolvimento, como definimos, mas, sim, numa categoria de armadilha, que serve para excluir os estudantes.

Desta forma, se utilizarmos a teoria pedagógica que considera a retenção da informação para a medição do progresso do estudante, os dados serão qualificados diante desse conhecimento. Porém, se a teoria pedagógica tem em conta o desenvolvimento da criança na formação de suas habilidades de compreender, analisar, sintetizar e aplicar, os dados coletados serão qualificados, positiva ou negativamente, diante dessa necessidade pedagógica.

Para qualificar a aprendizagem do educando temos que ter convicção da teoria que utilizamos em nossa prática pedagógica, e, além disso, considerar o planejamento de ensino que estabelecemos como um guia. Sem esta convicção e o planejamento de ensino, que consiste na teoria pedagógica, os atos avaliativos se tornariam práticas aleatórias, e sem vínculos com a realidade educativa dos alunos (LUCKESI, 2000).

A avaliação Diagnóstica e o ato de avaliar, para se completarem, necessitam de uma tomada de decisão. A decisão do que fazer se impõe no ato de avaliar. A avaliação não se encerra com a qualificação do estado em que se encontram os alunos ou professores, ela obriga a decisão, que não é neutra, e a avaliação se completa com caminhos mais adequados e satisfatórios para uma ação. Luckesi (2000) afirma que o ato de avaliar implica na busca do mais satisfatório estado daquilo que está sendo avaliado.

A avaliação da aprendizagem nos possibilita levar à frente uma ação que foi planejada dentro de um armação teórica, assim como política, não sendo qualquer resultado que satisfará, mas, sim, um resultado compatível com a teoria e com a prática pedagógica que estejamos utilizando. Luckesi (2000) ressalta que avaliar a aprendizagem escolar implica estar disponível para acolher os alunos em sua totalidade, de maneira compatível à teoria que orienta nossas práticas educativas, norteadoras do ato de avaliar e diagnosticar.

Sendo assim, Luckesi (2000) conclui que a prática da avaliação da aprendizagem, para manifestar-se como tal, deve apontar ser democrática e inclusiva, não voltada para a seleção, como os exames e não vinculada à submissão, ao medo, mas à espontaneidade no processo de busca por novos conhecimentos.

\subsection{Avaliação Classificatória em relação à Diagnóstica}

Hoffmann (2010), nesta conjuntura, alude a que os educandos apresentam maneiras peculiares e diferenciadas de vivenciar as situações cotidianas, de interagir com os objetos e com o meio.

O desenvolvimento do educando acontece de forma frenética, e a cada instante este realiza novas conquistas e descobertas, ultrapassando nossas expectativas, ocasionando fascinação, ao observarmos seu modo de agir, em suas brincadeiras e em suas expressões. As ações educativas nas instituições possibilitam que a cada dia se torne mais importante essa atitude de observar, analisar e refletir quanto à continuidade do caminho pedagógico adotado.

Nesse sentido, Cesar e Souza (2016) acrescentam que, ao avaliar o educando, nos envolvemos afetivamente, logo, a relação educador/educando também se define por meio de práticas avaliativas. Assim, o desafio de avaliar não se refere a medir, comparar ou julgar, mas, sim, a acompanhar o desenvolvimento contínuo das crianças. 
Os equívocos e limitações cometidos no processo de avaliação na educação infantil são decorrentes de um sistema cuja estruturação é debilitada visto que os resultados computados pelas escolas são incoerentes com a realidade vivenciada pelos discentes, assim como a expectativa dos pais ou responsáveis sobre o desenvolvimento do educando é, comumente, opressora. (CESAR; SOUZA, 2016)

Nesse contexto, os autores Lacerda e Souza (2013) concordam que a avaliação não tem o objetivo de exercer controle sobre o aluno, mas, sim, o de favorecer a melhoria do ensino e da aprendizagem. A avaliação Diagnóstica na educação infantil acontece durante todo o processo de ensino e aprendizagem e utiliza como mecanismos: a observação, o acompanhamento da evolução e das dificuldades que o aluno apresenta, e os registros relevantes desse processo.

O termo avaliação, na visão tradicional, é compreendida como forma de mensuração das habilidades do educando, inibindo sua criatividade e distorcendo sua aprendizagem, pelo simples fato de sentir-se intimado em realizar as avaliações formais, tendo sentimentos de tensão, medo, desconfiança de seu potencial, o que favorece os erros constantes dos educandos, em relação a estas avaliações. Ao contrário, na escola crítico-social, a avaliação é considerada um aspecto qualitativo, como mecanismo de compreensão do processo de desenvolvimento do aluno e do próprio ensino.

Assim, em retorno às proposições de Hoffmann (2010), a autora apresenta dois pressupostos básicos de uma proposta de avaliação para educação infantil: 1) a observação atenta e curiosa sobre as manifestações de cada educando; 2) e a reflexão sobre o significado dessas manifestações retratadas pelos alunos.

Freire (1994, p. 21), por sua vez, aponta que

É procurando compreender as atividades espontâneas das crianças que vou, pouco a pouco, captando os seus interesses, os mais diversos. [...] Por isso é que, em última análise, as propostas de trabalho nascem delas e de mim como educadora. Não é de se estranhar, pois, que as crianças se encontrem nas suas atividades e as percebem como algo delas, ao mesmo tempo em que vão entendendo o meu de organizadora e não de 'dona de suas atividades'.

A proposta da avaliação Diagnóstica contesta a concepção tradicional, conforme essa perspectiva, na medida em que se evidencia no observar e refletir para dar continuidade às ações educativas. Em outras palavras, a ação avaliativa na educação infantil deve ser essencialmente contrária a uma concepção de julgamento de resultado.

Hoffmann (2010), por sua vez, ressalta a visão da avaliação numa perspectiva libertadora, ou seja, o ato de avaliar como uma prática coletiva a qual exige consciência crítica e responsável de todos os envolvidos no processo.

Faz-se necessário, assim, que a clássica forma de avaliar, procurando os erros e os culpados, seja substituída por uma avaliação significativa o suficiente para agregar elementos de crítica e de transformações competentes e dinâmicas em seu fazer diário.
É inseparável do processo avaliativo que a interação professor/aluno se desenvolva de forma subjetiva, em que o educador não se interesse somente pela aquisição cognitiva do educando ou, de maneira inversa, enfoque apenas nos cuidados para com a criança dando-lhe carinho e atenção, mas se esquecendo do planejamento pedagógico e do auxílio ao progresso intelectual deste (CESAR; SOUZA, 2016).

Dessa forma, é imprescindível que o educador planeje os acontecimentos assimilados pelos educandos e analise sua prática em sala de aula, tendo o esclarecimento de que as avaliações não poderão ser cobradas por meio de exercícios desvinculados da realidade do educando, nem por meros instrumentos de ordem ou disciplina (CESAR; SOUZA, 2016).

A avaliação que não considera o educando como o protagonista de seu conhecimento e aptidões resulta em uma prática contrária, desvinculada da realidade e das necessidades concretas das crianças. Ao julgar as ações do educando e atribuir-lhe toda a responsabilidade por um possível fracasso ou êxito educativo, surge uma comodidade, por parte dos educadores, na avaliação Classificatória. Hoffmann (2010 p.75) afirma que

O cotidiano da creche é um tempo de liberdade vigiada, um tempo não produtivo. Fora a rotina estreita, as ordens estritas, vigia-se a criança para que cresça guardada, alimentada, protegida... uma vigilância, entretanto, que não lhe permite crescer de fato porque a limita nas suas possibilidades. Limita o seu presente, modela o seu futuro.

Neste contexto, Lacerda e Souza (2013) pontuam que o ato de avaliar na educação infantil se refere à necessidade de registrar o desenvolvimento e aprendizagem do aluno, a partir da observação das atividades exercidas no cotidiano escolar, tendo resultados eficazes de verificação da aprendizagem se vierem acompanhados do repensar do educador quanto a sua prática pedagógica e forma de avaliação adotada. Nesta concepção, a avaliação será compreendida como meio de mediar as competências do aluno, estimulando o educador a, em paralelo, refletir sobre suas ações pedagógicas no tocante à adequabilidade.

Apontamos, assim, para a importância de registros sobre o desenvolvimento da criança uma vez que possibilitam o acompanhamento do conteúdo assimilado, além de facilitar a mediação da aquisição do conhecimento, pois, quanto mais um conhecimento continuado e significativo for registrado, mais serão ampliadas as possibilidades de uma ação educativa e direcionada às demandas apresentados pelos próprios educandos.

Ao retomarmos as considerações de Hoffmann (2010), a autora elucida que a avaliação Diagnóstica contribui para a identificação das dificuldades do educando na assimilação do conhecimento, relacionadas ao desenvolvimento cognitivo quanto à identificação dos conteúdos do currículo pedagógico. Possui três objetivos principais: 1) identificar a realidade de cada turma; 2) observar o desenvolvimento individual de 
cada educando 3) e os processos de ensino e aprendizagem, refletindo sobre as causas das dificuldades recorrentes, definindo as ações do educador para sanar as dificuldades do educando.

Assim, a avaliação na educação infantil consiste no acompanhamento do progresso da criança, e devido a isso, necessita ser direcionada de modo a fortalecer a ação do educador no sentido de compreender que avaliar a aprendizagem e o desenvolvimento do aluno da educação infantil implica em ajustar o planejamento, o processo de ensino, o método de avaliar, e os instrumentos que contribuem para o seguimento de ensino.

Vale ressaltar que a ação docente é influenciada pelas tendências pedagógicas que, neste caso, perpassam educadores e educandos, provocando retrocessos ou avanços no ato de avaliar, transformando assim, a educação das instituições educacionais infantis. Há que se compreender que a avaliação Diagnóstica é um modelo aberto e flexível, que dá espaço às descobertas e favorece a aprendizagem e o desenvolvimento infantil (LACERDA; SOUZA, 2013).

A ação avaliativa no cotidiano da educação infantil exige do docente tomar consciência de que toda e qualquer ação deve ter por base uma intenção de assegurar um clima sem tensão e limitações, de modo que os educandos obtenham a confiança em suas habilidades, se desenvolvendo e vivenciando situações de forma própria e diferenciadas das dos docentes. Logo, repensar no significado dos registros da avaliação propõe aos educadores um exercício de reflexão sobre o educando em suas habilidades e limitações, bem como de suas escolhas enquanto prática pedagógica.

O significado dos relatórios de avaliação deve desvincularse de exigências burocráticas das instituições. Quando elaborados, precisam resguardar o princípio de favorecer o prestar atenção às crianças e ao seu desenvolvimento. Não podem ser elaborados com intervalos bimestrais ou semestrais, mas devem resultar de anotações frequentes, sobre o cotidiano dos educandos, de modo a subsidiar permanentemente o trabalho junto a eles, propiciando a busca por caminhos por parte do educador a fim de ampliar as conquistas dos estudantes no tocante ao protagonismo de sua aprendizagem.

Desta forma, os registros, as anotações sobre o desenvolvimento infantil, precisam ser complementados e compartilhados por todas as pessoas que se responsabilizam pela criança. A relação família/escola deve ser dinâmica a fim de gerar reflexão mútua sobre os interesses, as necessidades, as conquistas das crianças, no sentido de auxiliá-las em suas tentativas de aquisição de novos saberes. O que não quer dizer que deva efetivar uma prática de reuniões periódicas com os pais e ou responsáveis para entrega de pareceres finais, mas, ao contrário, significa criar oportunidades frequentes de troca de ideias entre os educadores que trabalham com as crianças e destes com seus familiares.

Portanto, a prática avaliativa na educação infantil compreende avaliar sua própria especificidade, ou seja, refletir sobre a dimensão em que se aborda o propósito do desenvolvimento pleno do educando em todos os aspectos, e que garanta, no projeto político-social, seu direito como criança.

\subsection{Avaliação Diagnóstica em sua Adequabilidade}

Kramer (1989) enfatiza que a educação de crianças de 4 a 6 anos no Brasil, nos últimos cinquenta anos, passou a ser considerada como dever do Estado e direito de todos os cidadãos. Unicamente, a partir de 1971, com a lei 5692, a educação básica foi prolongada de quatro para oito anos de duração, considerada obrigatória em todo o estado nacional. Se observamos atentamente, o quadro de crianças de 0 a 6 anos é ainda mais grave, pois somente na década de 70 a importância da educação da criança é reconhecida e as políticas governamentais começam a ampliar seu atendimento.

A Nova Carta Constitucional reconhece o dever do Estado de oferecer creches e pré-escola para todas as crianças de 0 a 6 anos. A fim de que seu reconhecimento se transforme em realidade, fazendo com que a educação pré-escolar se torne verdadeiramente pública, é necessário que haja legislação e recursos específicos, estabelecidos não só pela nova Lei de Diretrizes e Bases de Educação Nacional, mas também pelas constituições Estaduais (KRAMER, 1989).

Segundo Kramer (1989), compete dizer que a educação de crianças de zero a seis anos precisa orientar-se por uma visão das crianças como indivíduos que vivem em sociedade como sujeitos ativos, e que se levem em consideração suas diferenças históricas, classe sociais, etnias e sexo.

Para Kramer (1989), o processo de desenvolvimento infantil nos permite distinguir áreas como: sensóriomotora, socioafetiva, simbólica e cognitiva e, assim, podese compreender de que forma as crianças constroem o seu conhecimento, cujo entendimento auxilia a prática pedagógica nos diferentes níveis escolares, na medida em que podem orientar os professores sobre o que as crianças são capazes de descobrir e aprender a cada momento. Com isso, as crianças atuam na construção de seu conhecimento como sujeitos ativos, fazendo uso dos esquemas mentais próprios a cada etapa de seu desenvolvimento.

No tocante à etapa de desenvolvimento infantil, cabe ressaltar o esclarecimento de Jean Piaget (KRAMER, 1989), de que este resulta de combinações que o organismo traz em associação com as circunstâncias oferecidas pelo meio, ou seja, o eixo central é a interação organismo/meio. Essa interação se dá através de dois processos simultâneos: a organização interna e a adaptação ao meio, funções exercidas pelo organismo ao longo de toda a vida.

Os estágios de desenvolvimento piagetianos evoluem como uma espiral, não há definições de idades rígidas para os estágios, embora se apresentem em uma sequência constante: a) o sensório-motor, simbólico; b) operatório 
concreto e operatório abstrato; considerando que tal processo de desenvolvimento é influenciado pelos seguintes fatores: 1) maturação; 2) exercitação; 3) aprendizagem social; 4) equilibração (KRAMER, 1989).

No tocante à avaliação, nesse contexto de estágios do desenvolvimento infantil, Schlindwein e Dias (2018, p.142) acrescentam que

A avaliação pode contribuir para o envolvimento profícuo desta tríade, na medida em que se propõe olhar de dentro o dia a dia educativo, elaborado, vivido e cotejado em sua intensidade e complexidade, a partir de dimensões e indicadores negociados entre estas partes. Em síntese, a criança e os estudos sobre a infância ocupam, na contemporaneidade, papel de centralidade. Olhar para a criança significa mobilizar um olhar pluridisciplinar. A atuação do professor na Educação Infantil significa pensar na criança como um ser humano em constante relação com seu contexto de vida.

Considerar o contexto social e cultural da criança significa reconhecer que elas são diferentes e têm especialidades, hábitos, costumes, valores presentes na família e na localidade, os quais influenciam na sua percepção de mundo. Deve-se, ainda, levar em consideração os hábitos, valores e costumes dos profissionais que com elas convivem no contexto escolar. Kramer (1989) evidencia que as relações estabelecidas entre os profissionais, as crianças, as famílias e a comunidade precisam ser norteadas por essa visão real da heterogeneidade que caracteriza a sociedade e as escolas em geral. Essa diversidade nos coloca o desafio de buscar as alternativas necessárias para atender às crianças, compreendendo-as a partir das suas experiências e condições concretas de vida.

É irrefutável a relevância da estreita relação com as famílias, por parte das instituições educativas, como mencionado acima, não só para conhecê-las melhor, mas para que possam conhecer a proposta pedagógica e ajudar a construí-la na prática, facilitando assim um real diálogo entre escola e família, o que possibilita um contexto educacional no qual as contradições e dificuldades possam ser enfrentadas em benefício da criança. (KRAMER, 1989)

Para Kramer (1989), esses pressupostos teóricos estabelecem as diretrizes do trabalho com as crianças de 0 a 6 anos, e dão os fundamentos a partir de procedimentos e estratégias metodológicas e noções de conteúdos básicos das diferentes áreas do conhecimento. Nesse sentido, não há padrões ou requisitos únicos para a implementação deste currículo que pode, portanto, ser desenvolvido em circunstâncias diversas ou adaptadas.

Schlindwein e Dias (2018) corroboram que a avaliação se faz mediante a relação educador/educando, instituição/família e instituição/família/sociedade, a partir de uma concepção dialógica que caracteriza o fazer pedagógico com crianças. Assim, garante-se uma educação baseada no entendimento de que a avaliação se constitui como um ato praxiológico, respondendo à imbricação teoria e prática, no cotidiano educativo.

Na percepção da Kramer(1989), as tendências pedagógicas da educação pré-escolar não são simples, principalmente se entendemos que a realidade é mais dinâmica e contraditória do que as tipologias ou classificações que dela se fazem. Em contrapartida, nenhuma prática é neutra, como já defendido neste estudo: ao contrário, ela está sempre referenciada em alguns princípios e se volta a certos objetivos, mesmo que não formulados explicitamente.

A tendência do desenvolvimento natural, por exemplo, se identifica com o surgimento da educação pré-escolar, no século XVIII, com os princípios do liberalismo. Com princípios básicos da escola nova, destacam-se a valorização dos interesses e necessidades da criança; a defesa da ideia do desenvolvimento natural; a ênfase no caráter lúdico das atividades infantis e a crítica à escola tradicional. (KRAMER, 1989)

A discussão sobre a possibilidade de uma educação pré-escolar crítica é muito recente no Brasil. O movimento pedagógico pode ser caracterizado por sua dimensão social, demostrada através da defesa de uma escola centrada na criança, vista não como indivíduo isolado, mas como parte de uma comunidade, e que possui direitos e deveres dentro os quais o direito ao erro. Nesse contexto, Celestin Freinet (KRAMER, 1989) constrói uma pedagogia, não um método, mas técnicas com base na experimentação e documentação, destacando a participação da família, comunidade e escola, compreendendo que a aquisição do conhecimento é fundamental, conquanto que garantida de forma significativa e prazerosa.

Para que esse objetivo seja concretizado, definimos as seguintes metas educacionais: a construção da autonomia e da cooperação, o enfrentamento e a solução de problemas, a responsabilidade e a solução de problemas, a criatividade, a formação do autoconceito estável e positivo, a comunicação e expressão em todas as formas, particularmente ao nível da linguagem. É em função dessas metas que o currículo é pensado e a prática pedagógica desenvolvida. (KRAMER, 1989)

Com base nestes pressupostos, a escola leva em consideração os esquemas da assimilação da criança, favorecendo a realização de atividades desafiadoras que promovem desequilíbrio e reequilibrações sucessivas, fomentando a descoberta e a construção do conhecimento. Assim, os principais objetivos da educação consiste na formação de homens "criativos, inventivos e descobridores" na formação de pessoas críticas e ativas e, fundamentalmente, na construção da autonomia. (KRAMER, 1989, p. 37)

Neste contexto, conforme Ciasca e Mendes (2009), a legislação da educação brasileira apresenta a avaliação como ponto crucial para o desenvolvimento da aprendizagem do educando, explicitada no Art.31, da Lei de Diretrizes e Bases da Educação, que diz: "Na Educação Infantil a Avaliação far-se-á mediante acompanhamento e registro do seu desenvolvimento, sem o objetivo de promoção, mesmo para o acesso ao Ensino Fundamental" (BRASIL, 1996). 
Compreende-se que a avaliação deve ser, portanto, uma situação vivenciada pelo educando, observada e registrada pelo educador, preparado para efetuar os registros e ter domínio sobre as teorias do desenvolvimento infantil, abarcando o momento e as necessidades de cada um dos discentes. $\mathrm{O}$ educador deve ser o facilitador para que novas descobertas sejam realizadas. Não de forma passiva, mas, estimulando, permitindo, incentivando e proporcionando situações que promovam o progresso da autonomia.

O Referencial Curricular Nacional para a Educação Infantil (BRASIL, 1998, p.59), em sua Introdução, no item "Observação, registro e avaliação formativa", em similaridade com a legislação da educação brasileira, define que avaliação: "[...] é um conjunto de ações que auxiliam o educador a refletir sobre as condições de aprendizagens oferecidas e ajustar a sua prática às necessidades colocadas pelos educandos". Ou seja, avaliar, não é uma ação Classificatória, punitiva ou promocional.

\section{Conforme o documento:}

É um elemento indissociável do processo educativo que possibilita ao professor definir critérios para planejar as atividades e criar situações que geram avanços na aprendizagem das crianças. Tem como função acompanhar, orientar, regular e redirecionar esse processo como um todo. (BRASIL, 1998, v.1, p.59)

No volume 2 do Referencial Curricular Nacional para a Educação Infantil (BRASIL, 1998, p.65), o documento "Formação Pessoal e Social" orienta o educador a observar de forma cautelosa o desenvolvimento infantil do educando, sua concentração e envolvimento nas atividades e sua satisfação com as produções e conquistas para o acompanhamento e a avaliação, permitindo um replanejamento da ação pedagógica: "No que se refere à avaliação, deve-se ter em conta que não se trata de avaliar a criança, mas, sim, as situações de aprendizagem que foram oferecidas" (BRASIL, 1998, v.2, p.66).

Já o volume 3 do documento aborda o "Conhecimento de Mundo", subdividido em movimento, música, artes visuais, linguagem decodificada e codificada, natureza e sociedade, e matemática. Para cada área apresentada, há uma orientação para o professor em relação à prática pedagógica que inclui a observação, registro e avaliação. Estes processos contribuem não somente para a aquisição do conhecimento adequado para a infância, através das atividades pedagógicas, mas também estão comprometidos com a transformação da realidade educacional.

Hoffmann (1996), por sua vez, desenvolveu trabalhos voltados diretamente para a avaliação na pré-escola, fundamentais para esta pesquisa. Inicialmente, a autora discute a avaliação no contexto da educação infantil, em que observa a distância entre o significado de avaliar, as propostas avaliativas, tecendo duras críticas às fichas de comportamento, tão comumente utilizadas e que não conseguem fornecer o pleno desenvolvimento infantil.
Deve-se levar em consideração o fato de que oficialmente não há exigência de padronização das avaliações, o que amplia as possibilidades e modelos de avaliar com maior riqueza de informação, do educando e do ressignificar da prática educativa conforme o seu contexto, sua realidade, as concepções de criança e de educação infantil.

Hoffmann (1996, p.19) define alguns pressupostos básicos para a avaliação nesse nível de ensino. Sendo eles:

a) Uma proposta pedagógica que vise levar em conta a diversidade de interesses e possibilidades de exploração do mundo pela criança, respeitando sua própria identidade sociocultural e proporcionando-lhe um ambiente interativo, rico em materiais e experiências;

b) Um professor curioso e investigador do mundo da criança, agindo como mediador de suas conquistas, no sentido de apoiá-la, acompanhá-la, favorecendo o acesso a novos desafios;

c) Um processo avaliativo permanente de observação, registro e reflexão acerca do pensamento das crianças, de suas diferenças culturais e de desenvolvimento, embasado do repensar do educador sobre o fazer pedagógico.

Miguel Zabalza (1998), do Centro de Formação de Professores e Educadores de Infância da Universidade do Minho, relata uma experiência em que os professores são orientados a utilizar um conjunto de observações e registros de episódios relevantes, os quais estão organizados em seis categorias de desenvolvimento: 1- iniciativa; 2- relações sociais; 3- representação criativa. 4- música e movimento; 5- linguagem e competência na leitura e na escrita; 6- lógica e matemática. Para cada categoria de desenvolvimento, estão definidas experiências-chaves para orientar as observações e registros, permitindo observações em momentos diferenciados de cada educando.

Em contrapartida, Dahlberg, Moss e Pence (2003, p.192) apresentam uma concepção sobre observação, em que defendem o seguinte:

[...)] a 'observação da criança' diz respeito principalmente à avaliação do fato de ela estar adaptada a um conjunto de padrões. A 'documentação pedagógica' [...] diz respeito principalmente à tentativa de enxergar e o que a criança é capaz de fazer sem qualquer estrutura predeterminada de expectativa e normas.

Quer-se dizer, a observação assume uma verdade objetiva que pode ser registrada, enquanto a documentação é uma construção social do educando em relação ao meio, dividindose em dois momentos: I- O conteúdo material que registra o desenvolvimento do discente, dentro das expectativas do trabalho do pedagogo; II- O processo que envolve o uso deste material como meio de reflexão sobre o trabalho pedagógico, fazendo-o de maneira democrática.

Gandini e Goldhaber (2002) desenvolveram estudo sobre a documentação e analisaram alguns aspectos essenciais à sua construção. A construção da documentação é dividida em: a) a observação e o registro; b) as ferramentas de observação; c) a preparação das observações registradas para analisálas em conjunto; d) a divisão, reflexão e interpretação das 
observações. Devem-se relacionar as vantagens desse tipo de comunicação com a experiência de revisar a documentação com os educandos, o potencial para a avaliação autêntica e a comunicação com as famílias para estimular a participação.

Já para Kramer (1989), não só na educação infantil, mas nos demais níveis do sistema escolar, os avaliados são únicos e exclusivamente os educandos. Por isso, é necessário analisar criticamente essa prática, pois o fato de a maioria das vezes os alunos serem o único objeto de avaliação revela a estrutura de poder e autoritarismo da maioria das instituições escolares.

Ressalta-se, assim, a necessidade de que a clássica forma de avaliar, buscando os erros e os culpados, seja substituída por uma dinâmica de avaliação capaz de trazer elementos de crítica e transformação ativa, destacando o desenvolvimento do educando, suas habilidades: afetiva, emocional e cognitiva. Assim, constituiria o suporte fundamental para a construção da formação, e de leitura de mundo do educando.

\section{Conclusão}

A avaliação, portanto, deve se apresentar de forma significativa e permanente, valorizando todos os aspectos do desenvolvimento da criança, em especial na educação infantil, pois o ato de avaliar implica no modo como observamos o mundo e somos capazes de responder as suas expectativas. Assim, repensar novas práticas pedagógicas propicia a tomada de consciência de certas inadequações que se registram, desencadeando a busca de alternativas mais assertivas e eficazes em relação à aprendizagem, ao valorizar e respeitar diferenças de desenvolvimento e de conhecimento em processo criativo, associadas ao prazer pela descoberta da construção de significados.

O corpo docente, comumente, concorda quanto à necessidade de avaliar, mas ao mesmo tempo relata a dificuldade desta ação pedagógica. $\mathrm{O}$ educador é o mediador da construção do conhecimento do educando, incentivando-o em suas habilidades e capacidades de criar seu conhecimento de mundo.

A avaliação só será eficiente e eficaz se ocorrer de forma interativa entre educador e educando, ambos caminhando na mesma direção, buscando objetivos claros, precisos, desafiadores embora possíveis, que conduzem e incluem.

O educando é um ser social e político sujeito a sua própria construção e reconstrução de ideias. Logo, necessita observar que seus alunos, igualmente, são capazes de estabelecer uma relação cognitiva e afetiva com o meio em que vive, mantendo uma ação interativa, transformadora, libertadora com a sociedade.

Entendemos, neste estudo, que, para avaliarmos, necessitamos analisar a criança como um ser completo de potencialidades e dificuldades, de modo a conduzir este educando à aquisição de múltiplos conhecimentos sem classificá-lo, rotulá-lo, mas, sim, estimulando-o a ampliar sua experiência com o meio em prol da construção de caminhos significativos de construção do saber.
Concluímos, assim, que a avaliação na educação infantil acontece durante todo o processo de ensino e aprendizagem e o educador utiliza como instrumentos: a observação, o acompanhamento da evolução do educando e o registro. Permite-se, com tais métodos, que o professor perceba se os objetivos foram alcançados e, caso isso não aconteça, este saberá como intervir a fim de aprimorar suas abordagens. Reiteramos, assim, que este estudo entende ser a avaliação Diagnóstica a maneira mais adequada do ato de avaliar na educação infantil.

\section{Referências}

BRASIL. Lei n. 9394, de 20 de Dezembro de 1996. Estabelece as Diretrizes e bases da Educação Nacional. Diário Oficial da União, Brasília, 23 de Dezembro de 1996.

BRASIL. Ministério da Educação. Política Nacional de Educação Infantil: pelos direitos das crianças de zero a seis anos à educação. Brasília: SEB, 2006.

BRASIL. Ministério da Educação e do Desporto. Secretaria de Educação Fundamental. Referencial Curricular Nacional para a Educação Infantil. Brasília: MEC/SEF, 1998.

BRASIL. Referencial Curricular Nacional para a Educação Infantil. Brasília: SEF, 1998. 3v. CEARÁ. Conselho de Educação. Resolução n.361, de 21 de Julho de 2000. Dispõe sobre a Educação Infantil no Âmbito do Sistema de Ensino do Ceará. Diário Oficial do Estado de Fortaleza, Fortaleza, 24 de jun. 2000.

CESAR, J; SOUZA, N. Avaliação na educação infantil: o desafio de avaliar sem classificar. Rev. Scire, v.9, n.1, p.1-13, 2016

CIASCA, M.; MENDES, D. Estudos de avaliação na educação infantil. Est. Aval. Educ., v.20, n.43, p.293-304, 2009.

DAHLBERG, G.; MOSS, P.; PENCE, A. Qualidade na educação da primeira infância: perspectivas pós-modernas. Porto Alegre: Artmed, 2003.

FREIRE, M. A paixão de conhecer o mundo. Rio de Janeiro: Paz e Terra, 1994.

GANDINI, L.; GOLDHABER, J. Duas reflexões sobre a documentação. In: GANDINI, L.; EDWARD, C. (Org.) Bambini: a abordagem italiana à educação infantil. Porto Alegre: Artmed, 2002. p.150-169.

HOFFMANN, J. Avaliação mito e desafio: uma perspectiva construtivista. Porto Alegre: Mediação, 2010.

HOFFMANN, J. Avaliação na pré-escola: um olhar sensível e reflexivo sobre a criança. Porto Alegre: Mediação, 1996.

KRAMER, S. Com a Pré-Escola nas Mãos: uma alternativa curricular para a Educação Infantil. São Paulo: Ática, 1989.

KRAMER, S. A politica do pré-escolar no Brasil: a arte do disfarce. Rio de Janeiro: Achiamé, 1989.

LACERDA, A.; SOUZA, M. A avalição na Educação Infantil. Rev. Encontro Pesq. Educ., v.1, n.1, p.20-29, 2013.

LUCKESI, C.C. Avaliação da aprendizagem escolar: estudos e proposições. São Paulo: Cortez, 2011.

LUCKESI, C.C. O que é mesmo o ato de avaliar a aprendizagem? Rev. Pátio., v.3, n.12, 2000.

MARTINS FILHO, A.; CASTRO, J. Avaliação na e da Educação Infantil. Avaliação de Contexto. Pro.Posições, v.29, n.87), p.1123, 2018. doi: http://dx.doi.org/10.1590/1980-6248-2016-0155 
SILVA, G.R.; FREIRE, P.C.T.

SCHLINDWEIN, L.M.; DIAS, J. Avaliação de Contexto na Educação Infantil: diferenciação e conflito na formação docente. Pro.Posição, v.29, n.2, p.137-158, 2018. doi https://doi. org/10.1590/1980-6248-2017-0024

ZABALZA, M.A. Qualidade em Educação Infantil. Porto Alegre: Artmed, 1998. 